\title{
DOCUMENTOS
}

\section{Tertulia con Paul Desenne}

\section{A gathering with Paul Desenne}

\author{
por \\ Hermann Hudde \\ Escuela de Extensión Universitaria del New England Conservatory of Music, \\ Boston, Massachusetts, Estados Unidos \\ hhconcerts@yahoo.com
}

América Latina es el más grande repositorio de energía musical. Lo que le da un toque muy especial al continente en la música es la coexistencia de diversas capas activas e históricas; simultáneamente con la superposición, mezcla y colisión de culturas, las cuales ni los medios de comunicación ni el centralismo han sido capaces de reduciry controlar. Centenares de géneros, subculturas en ámbitos con códigos comunes, colocan a América Latina al frente del escenario musical mundial. Juntos, compositores e intérpretes de la nueva música de concierto latinoamericana deben compartir la emoción y el proyecto de llevar estos sonidos estimulantes y estas expresiones a las audiencias que piden una verdadera renovación en la actitud y en la intensidad musical ${ }^{2}$.

Paul Desenne

${ }^{1} \mathrm{El}$ autor de este documento quiere agradecer la colaboración del compositor Paul Desenne, Raúl Pessina, por sus sugerencias en la gramática del texto y de los reseñadores anónimos. Parte de la información biográfica del compositor fue provista por él mismo durante las dos entrevistas efectuadas en mayo de 2011, así como en el sitio en Internet del compositor: http://www.pauldesenne.com/. Existen otras fuentes biográficas acerca de Desenne en las tesis académicas de Rondón 2005 y Montilla 2010, además de una breve nota biográfica en Ramos 1998: 512. Todas la traducciones del inglés al español en el artículo han sido hechas por el autor.

2 Esta cita se produce como resultado de ser el acreedor de una comisión por parte del Quinteto Latino en el 2013.Ver http://quintetolatino.org/special-projects/commissioning-contest/ 2013-ql-commissioning-contest-winner 


\section{SINOPSIS BIOGRÁFICA}

Paul Desenne, compositor latinoamericano nacido en Venezuela el 7 de diciembre de 1959, es un artista cuya música rompe con la rigidez de las tradiciones y las nociones absolutas, creando con sus piezas un puente entre músicas. Paul Desenne se inicia en el mundo de la música con un grupo formado con amigos. Asimismo toma lecciones de guitarra con Maurice Reyna (1948) -hijo del cuatrista Fredy Reyna (1917-2001)-y de composición con el músico griego Yannis Ioannidis, patrocinadas por el gobierno venezolano por medio del INCIBA (Instituto Nacional de Cultura y Bellas Artes). En 1976 Desenne se establece en Francia, donde estudia en el Conservatoire National de Région de Boulogne Billancourt y el Conservatoire National Supérieur de Paris; además de trabajar como músico en calles, bares y locales de la ciudad con otros colegas latinoamericanos. Una vez de regreso en Venezuela en 1987, Desenne se integra como chelista a la Orquesta Sinfónica Simón Bolívar y enseña en el IUDEM (Instituto Universitario de Estudios Musicales). Sus obras han sido interpretadas, tanto en Venezuela como en el extranjero, por agrupaciones como I Musici de Montreal, la Camerata Criolla de Caracas, la Kremerata Báltica, la Camerata de las Américas de México, la Orquesta Filarmónica de Bogotá, New Juilliard Ensemble, la Orquesta Filarmónica de las Américas, la Orquesta Sinfónica Simón Bolívar, Los Angeles Philharmonic, solo por nombrar algunas. Muchas de sus obras han sido grabadas en varios discos como: Tocatas Galeónicas (Dorian Records, 1990), Alzheimer (Independiente, 2000), Jaguar Songs (Cello Classics, 2010) y ha recibido premios y comisiones como por ejemplo: El Sistema, Caracas (2004, 2000), Fundación Banco Mercantil, Caracas (1998), Fundación Beracasa, Caracas (1998), Meet the Composer, New York (1995), Guggenheim Foundation (2009). Desenne también colabora con artículos mordaces para el diario El Nacional de Venezuela y la revista Número de Colombia y mantuvo con otros colegas un programa de radio llamado Alzheimer Cultural.

En esta ocasión conversé con Paul Desenne en el Instituto Radcliffe de Estudios Avanzados de la Universidad de Harvard de sus inquietudes como creador, sus "investigaciones musicales", su experiencia en Francia, sus estudios en Venezuela con Yannis Ioannidis y parte de sus reflexiones acerca de la música de concierto venezolana y latinoamericana, durante su residencia artística como compositor en dicha institución ${ }^{3}$.

\section{ENTREVISTA}

\section{H.H.: ¿Cómo ha sido la evolución artística y personal de tu lenguaje musical?}

P.D.: Bueno, no sé si hay una evolución, pienso que simplemente hay una acumulación. No creo mucho en el "progreso" como concepto. Lo que uno hace con cada obra que va creando es una investigación. Pueden ocurrir cambios, pero tienen que ver más con el momento de cada obra y su circunstancia que con una evolución. Una obra es una investigación personal y existe la ventaja de la escritura para un compositor, porque lo que hago es registrar el proceso de una investigación. Sí, hay obras que están conectadas con una especie de intercambiabilidad de estados emotivos por la dialéctica de las cosas; entonces se demuestra por ese eje de las emociones que no hay una continuidad evolutiva; simplemente una acumulación de retratos puntuales en un proceso de cambios. No quiero ver la lista cronológica de obras como una evolución y no quiero hablar de evolución porque eso sería decir que, por ejemplo, el universo de este disco viejo que tienes ahí, Tocatas Galeónicas (1990), ya pasó y fue superado, o que tiene un valor inferior a los trabajos más recientes

\footnotetext{
3 Ver la información en: http://www.radcliffe.harvard.edu/people/paul-desenne
} 
por un supuesto "progreso". Además, precisamente ubicando un conjunto de obras como las Tocatas en el marco de su contemporaneidad, aparecerían como un retroceso si fuera justo el concepto de evolución, y yo sostengo que no son retrógradas por ser tonales y en buena parte basadas en la música tradicional venezolana. Son simplemente distintas.

\section{H.H.: ¿Crees que todavía conservas tus ideales anteriores de investigación musical?}

P.D.: Sí, todavía siento que tengo los ideales investigativos de esa época, es decir, las preguntas siguen vivas, las que nutrieron ese trabajo; entonces, si son las mismas preguntas, más o menos las mismas obsesiones a lo largo de la vida, uno tiene la sensación de mantener el mismo frente de investigación, aunque cambien los objetos.

Concluyendo sobre este punto, creo que puedo hablar de acumulación. Simplemente, vives a través de circunstancias: un día conoces a un cuarteto de clarinetes, otro día a una violinista, a un director, una oportunidad de un contrato con una orquesta, una oportunidad de una beca. Entonces, uno se postula y tiene que hacer un trabajo en particular. La circunstancia de la fortuna de la vida o el infortunio o la dificultad, digamos, impone su huella en la trayectoria artística. Y si hay alguna "evolución" es simplemente en la manera de enfrentar las cosas que se van presentando.

\section{H.H.: ¿¿Cuáles son tus inquietudes para crear?}

P.D.: Uno siempre trabaja en base a carencias. La carencia es lo que te obliga a crear. Yo no detecto en mi entorno la música que quisiera escuchar y la quiero producir. No me gusta, ni me satisface lo que hay, entonces, trato de hacer algo que me guste. Así de sencillo.

La motivación es la carencia, es decir, no escucho, no oigo, no veo, no siento que algo me guste de verdad. Por eso, como creador ves atisbos de ideas que quieres reproducir y desarrollar. A veces son más los conceptos los que mueven que los sonidos mismos. En ese caso parto de una idea musical imprecisa, muy tenue y abstracta. Parto de ahí, de una idea más que de un sonido, de un destilado conceptual que emana de fuentes muy diversas, musicales, poéticas, filosóficas, teatrales, hasta producir una obra de puros sonidos. Muchas veces ocurre así: veo el ensamble, sopeso los conceptos y encuentro la dirección. Y también hay algo que no existe todavía, que insiste y se manifiesta embrionariamente, pidiendo encarnar en sonidos.

\section{H.H.: ¿¿ómo te inicias en el universo de la música?}

P.D.: La primera obsesión mía con la música fue hacer un grupo. Me encantaba la idea de imitar un poco a esos grupos pop.

\section{H.H.: ¿Cómo, por ejemplo, YES? 4}

P.D.: No, no tanto eso, sino incluso más primitivos y anteriores a la gran explosión del pop sinfónico comercial. Yo quería hacer un grupo donde pudiéramos hacer música entre amigos. En realidad la idea de la composición, de la planificación de un evento musical y de una especie de diálogo entre personas con diferentes papeles, como un teatro musical, me fascinaba. Entonces, yo quería hacer eso y, en esa época, estaba armando mi primer grupo con unos amigos del colegio y muchachos que conocí en la playa.

4 Banda inglesa de rock progresivo fundada en 1968. Ver http://www.yesworld.com/ 
Me acuerdo que durante una Semana Santa, conocí a Juan Francisco "Pico" Sans y a su hermano Andrés Sans 5 . Ellos tenían un adelanto considerable, estudiaban teoría, piano o guitarra en la Escuela de Música Juan Manuel Olivares y yo era solo un aprendiz, simplemente, y quería comenzar con el chelo, curiosamente, sin ninguna explicación ${ }^{6}$. Me gustó el chelo, no sé por qué; luego hay explicaciones metafísicas: la familia de mi madre era originalmente de Bohemia, tierra de Antonín Dvořák (1841-1904) y muchos otros grandes músicos, y en todas las familias de Bohemia hay un cellista, me enteré después de haber comenzado ${ }^{7}$.

\section{H.H.: Háblanos de tus estudios de composición en Venezuela con Yannis Ioannidis}

P.D.: Andrés Sans me dice: "Mira hay un curso de composición con un señor griego y están abriendo unas becas; te inscribes, te dan una beca y puedes ir por las noches a la Universidad Metropolitana, allá en San Bernardino, dos veces por semana ${ }^{8}$. Yo tenía 14 años y quería estudiar con alguien. ¡Yannis Ioannidis era un músico tan brillante $!^{9}$ Ioannidis en una sola sesión ya te podía ubicar el enfoque en una gran cantidad de nociones y conceptos, en cualquier nivel de formación que estuvieras al llegar a su clase. En su estricta realidad, fue un estudio que duró un poco menos de dos años en mi caso, pero que aclaró infinidad de cosas conceptualmente.

${ }^{5}$ Juan Francisco Sans es un musicólogo, compositor, profesor universitario y pianista venezolano y su hermano Juan Andrés era guitarrista, compositor y pedagogo musical. Ver las notas biográficas acerca de los hermanos Sans en Cedeño 1998: 596-597.

${ }^{6}$ Este Conservatorio de Música lleva el nombre del insigne músico colonial Juan Manuel Olivares (1760-1797) que enseñó en la Academia Oratorio San Felipe de Neri, popularmente llamada la Escuela de Chacao fundada por el presbítero Pedro Ramón Palacios Gil Arratia (1739-1799), conocido como el 'Padre Sojo'.

7 Javier A. Montilla escribió en su tesis: "En la parte materna, los dos abuelos de la madre de Desenne eran violinistas en Bohemia. Uno de ellos se cambió para el clarinete haciendo una buena y perfecta combinación para el Klezmer (clarinete/violín), de acuerdo con su ascendencia hebrea. Asimismo, un tío-abuelo de su madre, Andrew Grill, era un compositor de polcas y música de baile en los Estados Unidos". Ver Montilla 2010: 13.

8 Desenne aclara en la entrevista: "Ioannidis, en ese momento, dictaba dos clases: una en la escuela 'Juan Manuel Olivares' que era una clase diurna -una o dos veces por semana- y otra nocturna en la Universidad Metropolitana, patrocinadas ambas por el INCIBA (Instituto Nacional de Cultura y Bellas Artes) o quizás una de ellas por la 'Juan Manuel Olivares'. En aquel entonces, en la 'Juan Manuel Olivares', la clase de Ioannidis trataba las 'Técnicas Contemporáneas' y en la Universidad Metropolitana era un estudio más general, para alumnos más disparejos en su formación”. Asimismo agrega: "Ioannidis recibía sus honorarios de profesor pagado directamente por el INCIBA, que era una institución muy seria. Esa enseñanza que él impartía no tenía un eco en Venezuela; no tenía una resonancia porque no había con quién hacer nada más allá de un concierto ocasional organizado por la naciente Sociedad Venezolana de Música Contemporánea, asociada a y modelada sobre las Sociedades sureñas de Uruguay y de Argentina”.

${ }^{9}$ Yannis Ioanidis es un compositor, director de orquesta, organista docente de origen griego que vivió en Venezuela desde 1968 hasta 1976. Su labor musical en Venezuela, a pesar de ser relativamente breve, dejó una huella profunda en este país. Algunos de sus alumnos en el INCIBA son actualmente músicos venezolanos destacados como Alfredo Rugeles, Emilio Mendoza, Adina Izarra, Miguel Astor, Juan Francisco Sans y otros más. En 1969 se le otorgó el premio de composición Teresa Carreño por su obra Figuras. Del mismo modo, dirigió las orquestas de cámara del INCIBA y de la Radio Nacional de Venezuela. Ver Méndez 1998: 40. También se puede leer el escrito concerniente a Ioannidis del profesor Emilio Mendoza de la Universidad Simón Bolívar: http:/ / prof.usb.ve/emendoza/emilioweb/ diario/11-2-2000.html 
Ioannidis logró impactar a mucha gente en Venezuela con ideas muy bien estructuradas. Hablaba un castellano perfecto y era luminoso, transparente, sin ningún viso de personalismo, muy democrático, muy clásico en sus ideas, en sus planteamientos, pero también muy revolucionario en el sentido de que no aceptaba ese academicismo rancio que te pedía millones de años de estudio y demostraba que uno puede alcanzar la verdad a través, simplemente, de entender un concepto y del porqué surgía históricamente un concepto particular en el arte de una época. Tenía, literalmente, una visión radical de las cosas. Siempre estaba buscando las raíces y la explicación profunda a partir de una conversación muy equitativa, mayéutica, entre alumnos y profesor.

\section{H.H.: ¿Era interdisciplinario?}

P.D.: Sí, Ioannidis buscaba siempre la raíz cultural, fenomenológica, material, artística, histórica, filosófica para explicar algún objeto musical considerado en la clase: de dónde venía la armonía, de dónde venía tal detalle vocal o instrumental; es decir, era un radicalismo histórico casi materialista para entender los elementos determinantes en un género o en una partitura. Obviamente tenía un discurso "antitratados". Se burlaba frecuentemente y con fundamentos claros de estos, explicando lo absurdo de las reglas ahistóricas, intemporales, absolutas, en la armonía o el contrapunto. Era una mina de información porque él daba siempre mucha información para sustentar los análisis que hacíamos de la música vocal del siglo XVI y de Bach, sobre todo, muy profundo en gran detalle de las invenciones, de las fugas. Se escuchaba mucha música contemporánea y cantábamos música coral bajo su dirección ${ }^{10}$.

Ioannidis tocaba el piano e improvisaba extraordinariamente y con una modestia absurda; un músico -todavía vive- de excelentes facultades, gran instrumentista que dejó una huella importantísima en Venezuela. En esa época, creo que no fue apreciado por la comunidad académica de Venezuela, porque en ese momento ocurría una cosa muy curiosa: estaba naciendo el movimiento de orquestas juveniles de José Antonio Abreu (1939) ${ }^{11}$. Si Ioannidis, por ejemplo, hubiese llegado a Venezuela en la década de los noventa (90) teniendo a las orquestas más establecidas, los estudiantes del IUDEM ${ }^{12}$, ahí él hubiera tenido una gran cátedra, porque él sabía cómo hablarle a los estudiantes venezolanos, y en realidad sus ideas hubiesen encajado perfectamente en el Sistema ya maduro. Pero él llego en un momento en donde la música clásica era tierra de nadie. La brevedad de su permanencia en Venezuela explica eso.

H.H.: Tú has sido parte de ese movimiento, antes y después de tu estadía en Francia. ¿Cuál es tu opinión sobre este hecho en la historia musical de Venezuela?

P.D.: Abreu era un verdadero revolucionario, visto como un extravagante en esa época. Así aparecía el movimiento orquestal del Maestro Abreu en esa época; era impresionante la movilización de recursos y en realidad era una cosa excéntrica. Así lucía, dentro del orden de gastos que parecían exagerados, muy propios del período "Saudita" del primer gobierno

10 Desenne expresa que: "Siempre verás que el rasgo común entre todos sus alumnos es esencialmente una gran admiración por su espíritu democrático. Él estaba en Venezuela por un exilio político. Los coroneles gobernaban Grecia y era radicalmente de izquierda. Ioannidis era muy generoso con sus estudiantes. Sin discriminar. A todos les dirigía igual atención y tiempo. Un profesor muy justo, lo recuerdo como la imagen misma de la justicia”.

11 Este es el Sistema Nacional de Orquestas y Coros Juveniles e Infantiles de Venezuela fundado por el maestro José Antonio Abreu en 1975.

12 Instituto Universitario de Estudios Musicales en Caracas/Venezuela. 
(1974-1979) de Carlos Andrés Pérez (1922-2010). Entonces, ese movimiento naciente de Abreu en 1975 -que era el momento en el que yo estaba estudiando con Ioannidis- se enfrenta a los conservatorios donde enseñaban los profesores de la sinfónica ${ }^{13}$, el maestro Ángel Sauce (1911-1995) ${ }^{14}$ y los alumnos de la escuela del maestro Vicente Emilio Sojo (1887-1974). Es decir, todavía quedaba un problema en ciernes que era el de Abreu ante los conservatorios tradicionales. Tarde o temprano esa batalla a veces muy silenciosa la ganaría Abreu, después de varias décadas de trabajo, y él absorbería toda la educación musical de Venezuela.

\section{H.H.: ¿Cómo?}

P.D.: Abreu introdujo un fast-track, digamos, para aniquilar todo ese academicismo dormido de las escuelas "Juan Manuel Olivares" o, en Santa Capilla, la "José Ángel Lamas" en donde todo el mundo estaba en una especie de somnolencia eterna desde los días de Sojo ${ }^{15}$. Entonces, Abreu dijo: "Ya basta, vamos hacer una cosa para la Venezuela moderna. Mira todos esos jóvenes por ahí, todo ese talento esperando por nosotros". Seguramente, desde un punto de vista personal, Abreu sentía una gran frustración, porque siendo alumno de la escuela de Sojo, tenía aspiraciones musicales formidables, como las demostró en su obra posteriormente ${ }^{16}$.

\section{H.H.: ¿Qué otros eventos en esta época te impactaron como músico en Caracas?}

P.D.: En ese mismo momento Antonio Estévez (1916-1988) fundó el Estudio de Fonología Musical del INCIBA, siendo esto el nacimiento de la música electrónica en Venezuela. En ese capítulo nada estructurado salió de ahí, porque había una especie de ruptura y crisis de la autoridad académica en Venezuela. Todo esto (el movimiento de Abreu, la escuela de Fonología con Estévez, las clases de Ioannidis, la paralela formación de la Sociedad Venezolana de Música Contemporánea, y el incremento del patrocinio cultural en Caracas bajo la tutela del entonces gobernador Diego Arria y su programa "Caracas para Todos", con los conciertos de la Banda Municipal de Gerry Weil (1939) y sus amigos -entre los cuales estaba Edgar Saume (1950)-, parecía ser parte de un todo concertado de gran fermento musical en los años 1974-1976, pese a las grandes diferencias que existían entre todos estos polos de actividad ${ }^{17}$. Lo que vemos hoy del Sistema quizás nació en esa época muy rica y movida, con mucho gasto público en educación y cultura en la ciudad capital.

13 La Orquesta Sinfónica Venezuela fue fundada en 1930. Ver http://www.osv.org.ve/inicio.php

14 Ángel Sauce compositor, director de orquesta y coros y pedagogo musical que egresó de la Escuela de Música J.Á. Lamas y luego cursó estudios de postgrado en la Universidad de Columbia. Recibió el Premio Nacional de Música en 1948 y 1982. Para más información ver Peñín 1998: 602-603.

15 Santa Capilla la José Ángel Lamas es la escuela más antigua a nivel superior en Venezuela. Dicha institución cambió de nombre en varias oportunidades hasta llevar el actual.

16 Desenne mencionó que tuvo clases de chelo (no muy felices) con el chelista y compositor Carlos Teppa (1923-1997). La familia Teppa ha donado la colección de obras del compositor a Facultad de Artes de la Universidad de Chile y a Latin American Music Center de la Universidad de Indiana en EE.UU. Ver: http://music.indiana.edu/lamc/collections/teppa.shtml

17 Gerry Weil es un músico venezolano (nacido en Austria) que fue homenajeado por su excelsa carrera musical con el Premio Nacional de Música de Venezuela. Más información acerca del maestro Weil se puede encontrar en su portal en línea: http://www.gerryweil.net/home.html. De igual forma, Edgar Saume es un percusionista venezolano y educador musical, miembro fundador de El Sistema, y trabajó en la sección de percusión de la Orquesta Sinfónica Simón Bolívar. Para leer respecto de Edgar Saume, ver Guido 1998: 603-604. 


\section{H.H.: ¿Puedes desarrollar un poco más esta idea?}

P.D.: La Venezuela académica que había tenido su gran era en la plástica, en la arquitectura, digamos, de la Universidad Central de Venezuela en los años 50, en la música, también, había tenido algunos grandes momentos con la época de Alejo Carpentier (1904-1980) ${ }^{18}$ en Venezuela y la Orquesta Sinfónica de Venezuela, época en que Antonio Estévez compone la Cantata Criolla. Pero entonces, llega esa ruptura, justo después, en los años 60, donde vemos un movimiento folklorista y nacionalista que surge con la democracia y el éxodo rural, pero no hay un movimiento nacionalista equivalente a nivel de la composición. O sea, el relevo de la generación de Sojo no ocurre a tiempo. Ese es el drama. Hay una fractura ahí, muy importante. Todo esto que narro -lo de Abreu e Ioannidis- transcurre a los tres o cuatro años de la muerte de Sojo (1887-1974).

\section{H.H.: ¿Cómo fue tu vida musical en Francia?}

P.D.: Ahí fue cuando me di cuenta de lo que tenía en mi oído y en mi cabeza ${ }^{19}$. Venía de tocar muchos conciertos en Caracas con este grupo de músicos que habían sido mis amigos: músicos populares para nada académicos, salvo uno de ellos, Juan Francisco Sans que tenía estudios formales de piano. Yllegué a una ciudad extraña a los 16 años de edad; ciudad muy hermosa, pero humanamente horrible para mí, en aquel entonces. Busqué, poco a poco, refugio en mis compatriotas en el exilio. Allá conocí a varios arpistas llaneros; aprendí a acompañar esa música con el cuatro, aprendí a tocar maracas.

Tenía muchos compañeros que tocaban el arpa llanera de Venezuela; incluso, tocamos en el Metro, en bares, y aprendí a los 17 años a acompañar con el chelo a un cantante llanero que me enseñó su repertorio. Guillermo Jiménez Leal (1947), un barinés, muy buen compositor, poeta, coplero y era también muy buen cantante. Entonces, él tenía todo un repertorio de canciones y musicalizaba la letra de todos los poemas del poeta venezolano Alberto Arvelo Torrealba (1905-1971). Tenía todas esas canciones frescas; él las acababa de escribir. Él estudiaba musicología en la Sorbona, y estaba preocupado por una cantidad

18 El escritor cubano Alejo Carpentier vivió en Venezuela entre 1945 y 1959.

19 "Mientras estudiaba violonchelo en París tuve la oportunidad de revolcar mi instrumento en el anémico ambiente de la música no académica de Francia, en la periferia de los conservatorios. Cada combinación es para mí un capítulo, un crédito de mis estudios extramuros. Chelo con arpa llanera en el metro, que es música de cazadores recolectores de monedas, guahíbos de los túneles; chelo con acordeón de vallenato en las rumbas de los caribeños enloquecidos por el exilio y la oscuridad -ojo con el micrófono, que se me raya el chelo-; chelo con tumbadora, chelo con kemanchá de Armenia, con tambores y flauta de bambú de Guadalupe, con udy darbuká de Argelia; chelo con bandoneón tuberculoso de exiliado porteño. Mientras mi profesor, un estalinista trasnochado, descalificaba mi inclinación por un instrumento burgués diciéndome que yo, suramericano de la élite, me podía dar ese lujo únicamente por el petróleo venezolano, poniendo en duda mi talento y mi vocación inquebrantable, yo iba descubriendo en la música de América Latina y del mundo no occidental todo lo que le faltaba a él en los registros de la expresión y la autenticidad. Lo que nunca me atreví a contestarle era que él podía darse el lujo de tocar violonchelo porque Francia vendía armas en África y plantas de energía nuclear en Irán. Lo cierto es que la barrera de prejuicios que separa la música académica de las otras, en Francia, ha condenado hasta a la propia música tradicional francesa, de cualquier clase, a un empobrecimiento y un descrédito profesional inimaginables. La verdadera función ancestral y legítima de la música ya no se transmite en los conservatorios. Pocos son los músicos académicos que conocen y actúan a partir de esa verdad que ha asesinado lentamente, en una crisis que tiene ya un siglo, la naturaleza orgánica de la formación musical, así como el vínculo entre el público y los músicos cultos". Desenne, Paul, 2006, "El vientre de la vieja esfera", Revista Número, № 37. Una parte del extracto fue citado por Fernández, 2011. 
de ideas, casi ficciones, como el barroco musical latinoamericano. O sea, ya imaginaba la chipola llanera con clavecín que más tarde yo escribiría para su segundo disco que tardó 17 años en realizarse. ${ }^{20}$

\section{H.H.: ¿ Te influenció mucho?}

P.D.: Él me influenció mucho en esas preocupaciones, porque tenía esa obsesión, pero no tenía la técnica de composición para realizarla y me abrió la idea de una ficción barroca venezolana, basada en ese puente que existe entre el arpa llanera y la música de cuerdas. La mandolina, la bandola llanera, el arpa tuyera y, especialmente, la música y la composición barroca, que son cosas muy populares para un estudiante. Todo el mundo adora la música barroca: Bach, Vivaldi. Uno siempre tiene contacto con esa música porque es la que se toca primero en una orquesta. Es la música más accesible al joven, generalmente, la más dinámica, la más enérgica, mucho más que la música romántica.

Entonces, él inculcó en mi espíritu esa preocupación de la imaginación por crear un puente entre la música venezolana llanera, que tiene unos visos de clasicismo estilístico muy precisos, con la música orquestada para un ensamble barroco. Incluso, él tenía la obsesión de hacer un disco e hizo dos con el título Folklore de Cámara. Era una colección de cualquier cosa, por decirlo así; por ejemplo, canciones venezolanas cantadas con voz de bel canto. Una especie de Lied venezolano para soprano y conjunto criollo. ¡Un kitsch espantoso! Guillermo Jiménez Leal mezclaba eso que era una cursilería muy suya con cosas que sí tenían más sentido para mí, por ejemplo: hacer un pajarillo con saxofón. A partir de su bagaje cultural personal, componer un pajarillo que tuviera la libertad de fraseo del saxo soprano, pero con toda la gramática estilística y el fraseo de una voz llanera. ¡Y eso era una novedad! Eso no se había pensado, porque los arreglos de música venezolana siempre eran orquestaciones de una melodía congelada, preexistente. ¡Una orquestación casi wagneriana de melodías folklóricas! Una chabacanería inaudible, porque la única cosa que los arreglistas tomaban en cuenta era la melodía extraída con fórceps de la música venezolana y orquestada un poco a lo Hollywood. ¡Una cosa espantosa! Él no tenía esa idea... Quería otra cosa mucho más profunda.

Jiménez Leal tenía una cosa radicalmente diferente que era escribir en la orquestación, según sus propias palabras, el gesto de la geometría. Él no tenía conocimientos de orquestación ni nada, pero decía: "Tú ves una partitura de Mozart y se ve la geometría". No era absurdo lo que decía, que la música llanera debía tener su propia geometría en la página. Lo que verdaderamente estaba señalando ahí era la textura musical. Es decir, se estaba refiriendo a algo que sí era revolucionario, que no era armonizar solamente una melodía. Tú no estás agarrando una melodía y orquestándola, sino que estás hablando de texturas, de una cosa más avanzada. Y esa idea de usar la textura musical y no una

20 Según Carlos García: "La chipola es una variedad formal de los golpes llaneros que a su vez forman parte de la familia del joropo llanero. Se caracteriza por el uso de un motivo melódico instrumental que se reitera en forma de ostinato sobre una armonía cíclica de T-Sd-D7; su diferencia con otros golpes reside -además del motivo melódico- en el carácter modulante de su armonía, ya que el ciclo mencionado generalmente se inicia en modo mayor, luego modula al relativo menor de la tonalidad original para luego recapitular. La extensión de las secciones tonales, así como el cambio a cada una de ellas, queda a discreción del ejecutante del instrumento principal, generalmente el arpa o, en su defecto, la bandola llanera. Al intervenir dos vocalistas en forma alternada $\mathrm{o}<<$ contrapunteo $>>$, los mismos deben poseer agilidad y destreza para afrontar la entonación de sus cuartetas en distintas tonalidades, hecho que convierte a la chipola en uno de los golpes más exigentes para los copleros llaneros". Ver García 1998: 376. 
melodía, un personaje, una entidad abstracta novelada románticamente. Fue una innovación conceptual en la escritura de la música venezolana de aquel tiempo.

\section{H.H.: ¿Qué más aprendiste con él?}

P.D.: Aprendí a acompañarle sus canciones y participé en sus pequeñas obsesiones de orquestador frustrado. Aprendí a hacer mis primeros arreglos de música venezolana con Jiménez Leal y a través de ese proyecto e incluso en ese año (1981), él grabó uno de mis arreglos de una de sus canciones. Arreglo bien difícil donde experimentaba con texturas que imitaban exactamente al cuatro venezolano entre las secciones de las cuerdas. Era una combinación básica de figuras rítmicas para orquesta de cuerdas que reproducía asombrosamente bien el charrasqueo del cuatro. Jiménez grabó ese arreglo en su disco y escribí luego otros arreglos más complejos y largos para un segundo disco que estaba en sus planes. Y esos arreglos durmieron durante 16 años. Recuerdo que eran tres arreglos y se grabaron en un segundo proyecto en 1996 en Caracas. Él me llamó; de hecho ya yo estaba viviendo en los bosques de Turgua, y dijo: "Tengo un proyecto; me dieron una plata". Entonces, se grabó su segundo disco Folklore de Cámara en 1996, financiado por el magnate de seguros barinés Tobías Carrero.

\section{H.H.: ¿Es decir que Francia fue una escuela de música latinoamericana para ti?}

P.D.: La consecuencia de mi estadía en Francia es que aprendí mucho de la música venezolana y del tango. Toqué en un grupo de tango con bandoneón, flauta, dos chelos y cantante. Aprendí mucho sobre la expresión del tango. No aprendí muchos tangos, quizás una veintena, pero aprendí la expresión, el estilo y la historia del tango. Además de unas cosas que uno no olvida como la importancia de la guitarra, y del bandoneón. Te estoy hablando del tango prepiazzollesco, por ejemplo: la música de Aníbal Troilo (1914-1975). El mejor disco de tango para mí es Troilo y Grela... el disco de guitarra y bandoneón. Después a Astor Piazzolla (1921-1992), lo aprecias ya de otra manera como el compositor que logra encontrar algo original, expresivo y universal que puede ser entendido en cualquier parte del mundo por un público ya harto de la música atonal. Es una especie de modernidad urbana con sonidos clásicos. Pero la escuela de tango que conocí era la Vieja Guardia, y fue una gran escuela de expresión en el chelo, siempre al tope del vibrato y del sonido, compitiendo contra el poder del bandoneón y la voz tremenda de Ernesto Rondó (1927-1992) ${ }^{21}$. Tocábamos en Café-concerts parisinos, y en giras, una incluso, sin el cantante, por Venezuela y Colombia en 1980. El grupo se llamaba Tango

21 Desenne escribió sobre Rondó: "Ernesto Pieroni, alias Rondó, cantante nativo de Rosario, de la misma camada de Julio Sosa, de voz potente en su ridículo disfraz de gaucho, folclor de postal que él creía obligatorio en el escenario del café concierto francés, nos llevó en su aventura a explorar el submundo totalmente desprestigiado del tango. Rondó estaba anclado en París desde los años sesenta, engañado por un típico contrato argentino, y se fue quedando, esperando en vano el regreso del éxito. «Mano a mano hemos quedado, no me importa lo que has hecho, lo que hacés y lo que harás»; ensayábamos repitiendo las famosas frases, amargos tangos de la vieja guardia, en el apartamento frente al cementerio del Père-Lachaise; éramos Jean-Marc, el violinista de ojeras profundas -zombi francés-; Consuelo la bogotana y yo en los violonchelos, y el inefable Oscar en el fuelle, máquina del tiempo que vomitaba sus verduritas del viejo barrio en los ventarrones que azotan la colina de los muertos... Rondó era como un Gardel, pero más gordo; su voz grave, siempre perfectamente afinada, cálida y espesa, tapiza el fondo de la música: crema de gomina junto a la pasta de los violonchelos". Desenne, Paul, 2006, "El vientre de la vieja esfera", Revista Número, N ${ }^{\circ} 37$. 
Cuatro. Yo le pagué el pasaje al bandoneonista Oscar Guidi quien luego se quedó en Venezuela un tiempo y fundó su grupo.

H.H.: Una vez de regreso en Caracas y como cellista miembro de la Orquesta Sinfónica Simón Bolívar, participaste en la grabación de los discos de Latin American Music Masters dirigidos por Eduardo Mata (1942-1995) para el sello Dorian Records.

P.D.: Sí, trabajar con Mata fue importante ${ }^{22}$. Lástima que el hombre confió demasiado en su poder como piloto de avión. La última vez que lo vi estábamos en el lobby del Carnegie Hall en el festival Voces de las Américas en diciembre de 1994. A las pocas semanas estaba viendo televisión en Boston y por casualidad sintonicé un canal de TV mexicano que estaba dando la noticia de su muerte en ese preciso instante. ¿Quedé paralizado! Supe que él tenía una buena opinión de mi primer CD e incluso supe que se lo mostraba a la gente, pero nunca me dijo nada. En aquella época de incertidumbre total, de gran depresión incluso debido a la imposibilidad de conseguir apoyo para mi trabajo, su ayuda hubiera sido clave; quizás lo tenía en sus planes, o quizás quería darle prioridad a sus amigos mexicanos... quedé con grandes dudas. Marcó una etapa importantísima para Venezuela, su rescate de la Cantata Criolla de Estévez señaló un camino que todavía estamos construyendo. Tomará tiempo, generaciones.

\section{H.H.: ¿Nos puedes comentar tu opinión sobre la composición y los compositores de Venezuela?}

P.D.: Creo que es una historia un poco triste. Nosotros tenemos uno de los mestizajes musicales más interesantes y una de las cosas más importantes de Venezuela es la tradición del arpa que tiene fuentes maravillosas: el arpa central y el arpa llanera. Tenemos ahí músicos y compositores fuera de lo común que han grabado su obra; no la han escrito. Los compositores venezolanos, en general, siempre han estado mirando afuera, incluso el mismo Vicente Emilio Sojo. Él se acercó un poco a lo venezolano, pero en la periferia de su obsesión con los géneros sacros universales y estaba obsesionado con la música de otra época. ¿Qué pasó? Se planteó la misma dicotomía que ocurrió entre las academias y el jazz, por ejemplo, o entre las universidades con su música contemporánea (postSchönberg) y el jazz ${ }^{23}$. En Venezuela ocurrió algo similar: los compositores académicos crearon el aparato con sus armonías y formas preexistentes y los compositores populares inventaron sus propios arreglos en las nacientes formas urbanas de la música venezolana.

Venezuela tuvo grandes compositores-arreglistas que se pasaron al bando de la música "popular", por decirlo de esa manera un poco llana y cruda, por ejemplo: Antonio Lauro (1917-1986). La guitarra tiene ese papel de puente entre la música "culta" y la música "popular" en Venezuela, aunque sea un puente artificial, porque en el fondo las categorías son casi irrelevantes porque cuando oyes la música de arpa tuyera dices: ¡esa es música culta! Fulgencio Aquino (1915-1994)24, compositor y arpista, sabía no centenares, sino miles de piezas según sus propias palabras, muchas de las cuales son sonatas como

22 Ver http:/ / www.sonoluminus.com/p-26-latin-america-alive-sbo-the-eduardo-mata-sessions.aspx

23 Desenne explica que: "La música simplemente saltó hacia el jazz y los verdaderos músicos creadores se fueron por ahí creando la gran música americana. Si me dicen, quién es el gran creador de los años 30: Duke Ellington (1899-1974). Él es el gran músico y orquestador de Norteamérica, porque organizó el material y creó un lenguaje buscando colores y formas, mucho más allá de los desarrollos de George Gershwin (1898-1937) o Aaron Copland (1900-1990)".

24 Se puede ver un documental/entrevista a Fulgencio Aquino hecho por el programa Voz y Raíz de un Pueblo en: http://www.youtube.com/watch?v=pYzn0NP_sDM 
las de Domenico Scarlatti (1685-1757). Los pasajes aragüeños son verdaderas sonatas desarrolladas para arpa diatónica, con algunos cromatismos ocasionales. Son verdaderas creaciones, obras individuales, es decir, son música culta sin papel ${ }^{25}$.

\section{H.H.: ¿Te refrieres a la riqueza y antigüedad de la música oral?}

P.D.: Sí, ese concepto hay que aclararlo un poquito. Pero la guitarra sí es un puente entre los dos mundos: el clásico, el escrito, el popular y el oral. ¿Qué hubiera hecho Lauro con un cuarteto de cuerdas o con una orquesta, más allá de las pocas piezas orquestales que compuso? ¿Qué hubiera hecho si en Venezuela hubiese habido un movimiento orquestal que les hiciera encargos a los compositores? ¿Qué hubiera escrito Antonio Lauro? Me pregunto qué habría hecho, porque él conocía la música popular; entonces, la idea era cómo esas texturas y ritmos se hubiesen podido expresar en un medio de música de concierto. La música de concierto te proporciona un escenario de amplificación y desarrollo para el imaginario musical de un pueblo y una cultura. Simplemente, una amplificación, un paso superior a una forma más colosal y desbordante. Pasas de la intimidad rural a

25 Paul Desenne escribió en su blog en español un texto de opinión acerca del origen histórico y el desarrollo del pasaje aragüeño en donde expresa: "Nadie puede explicar con precisión la difusión histórica del arpa central en Venezuela. Más que de un instrumento fabuloso, indiscutiblemente superior a sus pares del continente, hablamos de un cúmulo de obras y técnicas memorizadas provenientes del barroco español, corroborando que los Scarlatti, Soler, Bach y Vivaldi, navegaban majestuosos ríos de improvisación cuyas aguas se secaron misteriosamente en el siglo 18, dejando una mestiza descendencia americana. La generación espontánea no existe: las Revueltas Tuyeras y los Pasajes Aragüeños son el último eslabón del arpa ibérica, extinta, y del arte de tañer fantasía. Hoy sabemos que el arpa central de cuerdas metálicas y bordones de tripa o nylon nunca fue una imitación campesina del clavecín, sus cuerdas eran originalmente de tripa. Si bien el arpa de los jesuitas de Tópaga, Boyacá, que data de 1650, indica que la orden religiosa importó arpas para acompañar coros, nadie puede asegurar que el arpa se escapó de la iglesia. Pero los arpistas inmigrantes y sus fandangos quizás sí, ya que tres importantes arpas, la paraguaya, la jarocha y la colombo-venezolana rodean antiguos asentamientos jesuíticos. Sin embargo, la difusión de un instrumento completo (bajos y melodías) carente de mecanismos frágiles, se benefició de ser liviano y portátil a lomo de bestia en la quebrada topografía al sur de Caracas, primer asentamiento camino a los Llanos. Hubo sin duda una difusión secular, familiar y rural hasta en los valles más remotos. El arpa tuyera se distingue de la llanera por su sonido metálico parecido al clavecín que resalta la fineza de su tipleo, y porque se toca sin el cuatro, lo que indica que sus piezas son formalmente más complejas que las llaneras y que las sutiles digitaciones son más relevantes para la obra que la vuelta armónica que ocupan o que el golpe que marcan. Explico: estamos quizás ante formas mucho más destinadas al concierto y su nivel de atención que al zapateo: música de cámara. El gran arpista Fulgencio Aquino decía específicamente que algunas de sus composiciones eran para ser escuchadas, no bailadas ni cantadas; de hecho el noble Pasaje Aragüeño, en peligro de extinción, es un tipo de composición instrumental cuyo refinamiento impone el respeto de una escucha en silencio. Es fatal asociar el arpa central solamente con el golpe tuyero bailable que se fue simplificando con la amplificación y las cornetas hasta llegar a no ser más que un bordoneo repetitivo acompañando canciones necias en turbias cervecerías. En el rescate de esta música de altísima importancia han trabajado expertos como Arturo García, cultor y defensor muy elocuente del género; la musicóloga alemana Katryn Lengwinat, radicada en Venezuela, y artistas de otras esferas como Claudia Calderón, pianista que ofreció la primera versión de la Revuelta Instrumental de Aquino en el piano, incorporándola al repertorio pianístico venezolano (el salto al teclado eléctrico lo logró el sorprendente William Sigismondi, con su grupo de fusión de golpe tuyero 1, 2, 3 y Fuera). De las fuentes originales no se consigue casi nada comercialmente salvo la célebre grabación de Aquino producida por Luis Armando Roche en los 80. Inexplicable carencia. Hay tanto material original diseminado y frágil a la espera de una curaduría, de una publicación sin tintes políticos”. Ver el sitio: http://desenneprestissimo.wordpress.com/ 
un fenómeno urbano, porque las ciudades necesitan ese foro gigantesco, ese recinto donde se reúnen más de cien personas a escuchar una obra destinada a una comunidad más grande. Lauro tenía demanda a nivel internacional en el mercado de la guitarra, y compuso sin duda con esa expansión internacional de su mercado en mente, aunque ni la palabra mercado ni su idea hayan cruzado por su mente. Hoy el espacio del concierto está saturado por la música $p o p$ comercial, por cantantes chatarra y porquerías de baladas en conciertos espantosos. La producción musical está en manos de unos cuantos comerciantes y de unos tipos con criterios estéticos horripilantes, y tenemos que calarnos esa decadencia cultural, estética, como si fuera una gran cosa. ¡Esos son los verdaderos verdugos de la música: los medios hipercomercializados!

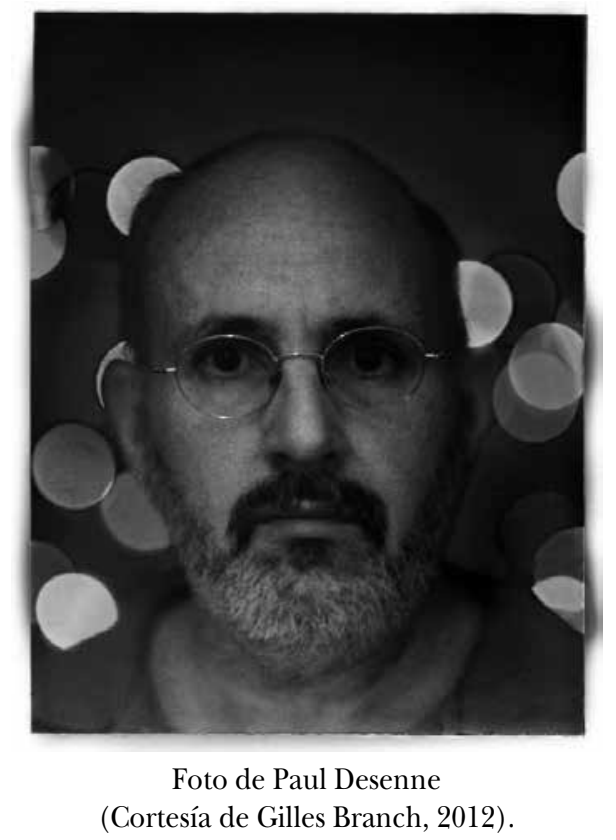

H.H.: ¿¿ú crees que a diferencia de Lauro y otros más, no hubo la visión de universalizar al nacionalismo venezolano, en la misma forma como lo hicieron Manuel de Falla (1876-1946) o Silvestre Revueltas (1899-1940)?

P.D.: Con las pocas excepciones puntuales, los compositores educados, formados, no supieron, en Venezuela, alzarse con ese lenguaje venezolano de altura, así como lo hizo Antonio Lauro con la guitarra; logrando cristalizar una obra, aunque muy buena, no produjo lo que esperabas; porque él ha debido escribir, con su creatividad, como 100 sonatas para guitarra y múltiples sinfonías y conciertos, con el inmenso material musical que conocía y frecuentaba. Lo mismo sucedió con Antonio Estévez. Él compuso dos o tres obras grandes y ya. Tiró la toalla. Claro, el caso es que quizás Estévez se dio cuenta de la vanidad de todo ese esfuerzo desplegado para escribir, ensamblar y tocar la Cantata Criolla, que se hizo dos veces solamente, para luego tenerla que engavetar por el resto de su vida como una obra "superada" por la música contemporánea "universal”. Estábamos muy lejos de la World Music, del renacimiento de la música étnica y de las voces regionales que ocurrió a mediados de los 90 . Esa es la frustración de tanto trabajo, pulir la obra, la grafía... y por esta razón 
no tenemos pasado musical, porque nadie se encargó de decirle a Estévez o a Lauro: ¡Es importante lo que estás haciendo! Y demostrarlo con apoyos reales, logísticos y materiales, contratos de encargos y conciertos.

Los compositores, la mayoría de las veces tenemos que trabajar en la imaginación; algo así como en la frase: "imagino que es importante para Venezuela y la cultura latinoamericana”. He llegado a pensar: si a nadie le importa, a mí no me importa. ¡Pero he llegado a la conclusión de que me importa a mí y otros verán si les gusta o no! Ya hice mi investigación y con la tecnología de hoy puedo escuchar las obras que hago con sonidos sintéticos. La gente del ambiente cultural ya no aprecia ni conoce el fenómeno del estreno de una obra y eso siempre escapa a la atención de los programadores y organizadores de conciertos que están atrapados en una rutina, cuyo diseño proviene del repertorio aprendido y no como en el teatro donde sí hay tres meses de ensayo para un montaje que se interpreta cien veces. En la música es la rutina de una semana de montaje y luego el concierto. Cuando las orquestas deberían pasar tres o cuatros meses ensamblando un programa y tocarlo durante varias semanas. La rutina orquestal es totalmente inadecuada y simplemente está diseñada para recordar obras maestras del pasado, no para crear los sonidos del presente que requieren mucho tiempo de producción y esmero. Esta estructura vetusta de ensayos de la orquesta sinfónica destruyó toda posibilidad de florecimiento y de diálogo entre la incipiente escuela del nacionalismo venezolano y el público que iba a los conciertos. Los profesores italianos y españoles, e incluso los venezolanos de la Orquesta Sinfónica Venezuela despreciaban no tan secretamente los experimentos de los jóvenes que se graduaban en las aulas de Sojo. Sin un diálogo entre compositores e intérpretes no hay salidas ni futuro. Lauro se salvó por tener su propia orquesta portátil en sus manos.

H.H.: ¿Cómo es tu visión sobre los compositores latinoamericanos como parte de la música clásica occidental?

P.D.: Los compositores de América Latina también tienen el mismo problema de ser eurocéntricos, en general, la mayoría. Por razones obvias, el arte de la composición se genera en Europa y la única manera de obtener estatura con muy pocas excepciones, provenía de un reconocimiento europeo o foráneo a estos compositores como es el caso de Heitor VillaLobos (1887-1959), Alberto Ginastera (1916-1983) y Carlos Chávez (1899-1978). Considero que hay una desigualdad fundamental. Nuestra apreciación es incompleta porque la música de concierto no refleja el gran talento musical de Latinoamérica, ni su potencial latente en ese mundo de la música de concierto.

La música de concierto refleja la frustración de las clases dominantes, e incluso de las clases medias, que buscaron implantar la cultura europea en Latinoamérica y que buscaron posteriormente crear una identidad regional que no pudieron quizás afianzar a través de esta música europea de concierto. Esto lo apreciamos claramente en México.

Pareciera que las sociedades criollas en Latinoamérica al principio trataron de fomentar la figura de los compositores románticos como Teresa Carreño (1853-1917). Vemos los esfuerzos de los burgueses criollos por tener algo que se parezca a un músico europeo, por afición sincera o por imitación de rasgos de clase; luego observamos la frustración de los músicos nacionalistas por tratar de imponer algo que no se puede hacer tan fácilmente importando esquemas. Es un paso incómodo en la adaptación de modelos culturales europeos en el siglo XIX.

En el siglo XX vemos grandes compositores en el tango, la salsa, en la música mexicana; es decir, hay compositores latinoamericanos extraordinarios inventando escrituras dentro, o a partir de los géneros populares, tradicionales, híbridos, urbanos, pero no registran presencia en lo académico, no ocurre lo que sucedió con el modernismo poético. Por ejemplo 
los arreglistas de la Sonora Matancera en Cuba (1924-2001), la música de Agustín Lara (1900-1970) o los compositores venezolanos tradicionales Eduardo Serrano (1911-2008) ${ }^{26}$, Ignacio Figueredo (1899-1995) ${ }^{27}$ o inmigrantes como Billo Frometa (1915-1988) ${ }^{28}$ derrochan talento, creatividad y recursividad, pero no articulan relación alguna, cuando no es negativa, con las academias. Hay un cosmos de creadores de música tradicional, de formas urbanas o semiurbanas y no tienen vínculo con la academia. Son totalmente extraacadémicos, inventan a la manera de Duke Ellington -gracias a la escritura-formas novedosas de organización sonora, procedimientos creativos realmente transformadores que la academia tradicional nunca logró entender o valorar, mucho menos incorporar o asimilar.

\section{H.H.: ¿Dónde crees que está el problema?}

P.D.: El problema está en la academia que no ha podido relacionar su entendimiento del mundo con la música latinoamericana que la gente escucha fuera de las salas del concierto clásico. Entonces, surge la "otra academia" alternativa, que nace y se desprende de la Etnomusicología, a partir del auge de la sociología histórica latinoamericanista, generalmente de izquierda; pero también a partir del mercado de la música comercial: las disqueras y el cine, incluso hollywoodiense -Carlos Gardel (1890-1935), Yma Sumac (1922-2008), Juan García Esquivel (1918-2002), etc.-. Entre los estudios y los discursos culturales sobre la música popular los hay que son asumidos también por personas que no tienen formación musical: no son músicos, sino sociólogos, historiadores de la cultura y no tienen ni la más remota idea de cómo funcionan los procesos composicionales. Por eso, especulan sobre fenómenos culturales que no entienden. A veces las explicaciones son totalmente pedestres y sencillas, se hacen y se publican aseveraciones absurdas y políticamente tendenciosas en la "musicología" universitaria de izquierda. Hay que saber de música para poder hablar de esos fenómenos y después hay que entender las culturas diversas de las regiones latinoamericanas para insertar estos discursos en la discusión sobre los fenómenos culturales propios, esto se hace muy poco.

Nuestros académicos que son los formadores de nuestros compositores deberían alimentar sus ideas en discusiones temáticas con sus colegas activos en la profesión, porque la composición musical no es que surja de la nada, sino que es un fenómeno colectivo, un modo de subsistencia, una realidad económica y material. Esa discusión se hizo siempre en un medio viciado y empobrecido musicalmente: las academias criollas de origen europeo, con sus prejuicios expresados en rígidas nomenclaturas y limitadas herramientas de análisis.

Nosotros tenemos que revolucionar no solamente nuestra visión, sino los centros donde se plantean los estudios musicales y culturales. Y tal vez, a partir de ahí podamos entender una relación entre nuestras tradiciones musicales de Latinoamérica-que son muchas y muy ricas- con las nuevas formas urbanas de concierto. Hemos llegado a tal punto que se cuestiona la existencia de estas últimas o incluso que desaparezcan en algunos centros urbanos latinoamericanos por la frustración presupuestaria de no poder conseguir fondos para mantener orquestas. Esa es otra realidad que la academia no registra.

Puede ser que en algún momento muera el atril y en hipótesis extremas retornemos a las formas de transmisión oral... No sé. Me ubico en una especie de punto en donde he

26 Eduardo Serrano fue un compositor que cultivó la música folklórica venezolana y la música para cine. Ver Moncada 1998: 614.

27 Ignacio Figueredo, arpista y compositor de la música del llano venezolano. Ver Ortiz 1998: $37-38$.

28 Billo Frometa, compositor, director y arreglista que fundó la orquesta de música popular Billo's Caracas Boys. Ver Ortiz 1998: 195-196. 
observado países con pirámides académicas como México, Colombia, Argentina y quizás Brasil -que no conozco muy bien- con una existencia de fuerzas que se oponen a la creación. Fuerzas burocráticas que impiden el financiamiento ágil de artistas; que bloquean el movimiento de creación, porque son burocracias que absorben el presupuesto y lo regulan como unos conserjes y no se dan cuenta de que se están comiendo la plata de los creadores. En vez de tener pocos administradores eficaces o incluso, idealmente, un robot administrador, tienen una gran estructura burocrática que se chupa los recursos. He visto en esas "pirámides", en varios países de la región, académicos burócratas que no hacen absolutamente nada productivo para la creación, simplemente reciclan la carroña del pasado y son felices con eso, produciendo literatura ministerial que nunca encuentra articulación práctica con la realidad; esto no tiene que ver con buenas o malas intenciones, sino con la inercia de las estructuras. Yo me sitúo al margen de todo esto, y por supuesto he visto serias limitaciones en mi carrera por expresar estas opiniones. ¡Afortunadamente, en Venezuela el Sistema ha sabido darle prioridad a la ejecución práctica de lo que se propone, no escribir informes! (perdonen el chauvinismo...risas...).

¡Muchas gracias por la conversación, Paul!

\section{BIBLIOGRAFÍA}

\section{CÁCERES, EdUARdo}

1989 "Los Cursos Latinoamericanos de Música Contemporánea -Una alternativa diferente-", Revista Musical Chilena, Año XLIII, julio-diciembre, No 172, pp. 46-84.

\section{Cedeño, Roberto}

1998 "Juan Francisco Sans” y “Andrés Sans”, Enciclopedia de la música en Venezuela. Editada por José Peñín y Walter Guido. Caracas: Fundación Bigott, pp. 596-597.

Fernández, Luis M.

2011 Paul Desenne's Sonata for Violin Solo: A Theoretical and Practical Study. Open Access Dissertations. Paper 535. Tesis para optar al grado de Doctor en Artes Musicales. Florida: Universidad de Miami, Facultad de Música y Danza.

García, Carlos

1998 “Chipola”, Enciclopedia de la música en Venezuela. Editada por José Peñín y Walter Guido. Caracas: Fundación Bigott, p. 376.

Guido, Walter

1998 "Edgar Saume", Enciclopedia de la música en Venezuela. Editada por José Peñín y Walter Guido. Caracas: Fundación Bigott, pp. 603-604.

MÉNDEZ, Josefina

1998 "Yannis Ioanidis", Enciclopedia de la música en Venezuela. Editada por José Peñín y Walter Guido. Caracas: Fundación Bigott, p. 40.

Mondaca, Fredy

1998 "Eduardo Serrano", Enciclopedia de la música en Venezuela. Editada por José Peñín y Walter Guido. Caracas: Fundación Bigott, p. 614.

Montilla, Javier A.

2010 The Flue Music of Paul Desenne: A Comparative Analytical Study of Representative Works (La música para flauta de Paul Desenne: Un estudio analítico comparativo de obras representativas). Tesis para optar al grado de Doctor en Artes Musicales. Lincoln: Universidad de Nebraska, Facultad de Música. 
Ortiz, Manuel Antonio

1998 “Ignacio Figueredo", Enciclopedia de la música en Venezuela. Editada por José Peñín y Walter Guido. Caracas: Fundación Bigott, pp. 37-38.

1998 "Billo Frometa", Enciclopedia de la música en Venezuela. Editada por José Peñín y Walter Guido. Caracas: Fundación Bigott, pp. 195-196.

Peñín, José

1998 “Ángel Sauce”, Enciclopedia de la música en Venezuela. Editada por José Peñín y Walter Guido. Caracas: Fundación Bigott, pp. 602-603.

RAmos, Graciela

1998 "Paul Desenne”, Enciclopedia de la música en Venezuela. Editada por José Peñín y Walter Guido. Caracas: Fundación Bigott, p. 512.

RoNDón, Tulio

2005 Cultural Hybridization in the Music of Paul Desenne: An Integration of Latin American Folk, Pop and Indigenous music with Western Classical Traditions (Hibridación cultural en la música de Paul Desenne: Una integración de las músicas folklóricas latinoamericanas, pop e indígenas con la tradición clásica occidental). Tesis para optar al grado de Doctor en Artes Musicales. Arizona: Universidad de Arizona, Facultad de Música y Danza.

\section{Fonogramas}

1995 Tocatas Galeónicas: Paul Desenne collected chamber works (1983-1989). CD B000001Q76. Boyce: Dorian Records.

2000 Alzheimer. CD FD 2522000947. Caracas: Producción independiente.

2004 El Reto: Leyenda de Florentino y el diablo. CD FD2522004356. Caracas: Gurrufío Records.

2010 Jaguar Songs: Collected cello works by Paul Desenne. CD B003JTUE8W. Londres: Cello Classics.

Sitios web

http://www.pauldesenne.com/ [con acceso el 19/1/2014].

http://www.radcliffe.harvard.edu/people/paul-desenne [con acceso el 19/1/2014].

http://quintetolatino.org/special-projects/commissioning-contest/2013-ql-commissioningcontest-winner [con acceso el 19/1/2014].

http://www.yesworld.com/ [con acceso el 19/1/2014].

http://prof.usb.ve/emendoza/emilioweb/diario/11-2-2000.html [con acceso el $19 / 1 / 2014]$.

http://www.osv.org.ve/inicio.php [con acceso el 19/1/2014].

http://music.indiana.edu/lamc/collections/teppa.shtml [con acceso el 19/1/2014].

http://www.gerryweil.net/home.html [con acceso el 19/1/2014].

http://revistanumero.net/2006/37vien.htm [con acceso el 19/1/2014]. 
http:/ / www.sonoluminus.com/p-26-latin-america-alive-sbo-the-eduardo-mata-sessions.aspx [con acceso el 19/1/2014].

http://www.youtube.com/watch?v=pYzn0NP_sDM [con acceso el 19/1/2014].

http://desenneprestissimo.wordpress.com/ [con acceso el 19/1/2014].

\section{Entrevistas}

Entrevista del autor con Paul Desenne en Cambridge, Massachusetts, 4 de mayo de 2011.

Entrevista del autor con Paul Desenne en Cambridge, Massachusetts, 18 de mayo de 2011. 